\title{
Fine structure of substorm and geomagnetically induced currents
}

\author{
Olga Kozyreva ${ }^{1}$, Vyacheslav Pilipenko*,1,2, Roman Krasnoperov² ${ }^{2}$ Lisa Baddeley ${ }^{3}$, \\ Yaroslav Sakharov ${ }^{4}$ and Michail Dobrovolsky ${ }^{2}$ \\ (1) Institute of Physics of the Earth, Moscow, Russia \\ (2) Geophysical Center, Moscow, Russia \\ (3) University Center at Svalbard, Norway \\ (4) Polar Geophysical Institute, Apatity, Russia
}

Article history: received May 8, 2019; accepted October 4, 2019

\begin{abstract}
The rapid changes $\mathrm{dB} / \mathrm{dt}$ of the Earth's magnetic field due to substorms can excite large geomagnetically-induced currents (GICs) that can have harmful effects on technological systems. This paper presents an analysis of the characteristics of $\mathrm{dB} / \mathrm{dt}$ enhancements observed in Fennoscandia using data from the IMAGE magnetometer chain along a geomagnetic longitude of $110^{\circ}$. The abrupt geomagnetic field variations may be associated with the substorm onsets, isolated magnetic impulsive events (MIEs), and quasi-periodic series of MIEs, known as Ps6 pulsations (periods 5-15 min). For a detailed examination of the latitudinal structure of $\mathrm{dB} / \mathrm{dt}$ enhancements and their association with the auroral oval boundaries we applied the technique of magnetic keograms. This simple technique helps to visualize and characterize the fine structure of substorm, namely the location in time and latitude of $\mathrm{dB} / \mathrm{dt}$ enhancements. The location of the auroral oval boundaries has been estimated with the OVATION-prime model. Among the different types of impulsive disturbances investigated auroral substorm onset provides the largest GICs (few tens of A). Isolated nightside MIEs are also effective in the excitation of GICs (>10 A). Ps6 pulsations are effective in the excitation of GICs with magnitude about $20 \mathrm{~A}$ and even higher. Monochromatic Pc5 pulsations are capable to induce noticeable GICs, up to $13 \mathrm{~A}$. Large localized disturbances on short timescales are the actual drivers of GICs, and they may be imagined like geomagnetic "strokes" during magnetospheric "thunderstorms".
\end{abstract}

Keywords: substorms, geomagnetically-induced currents, auroral precipitation, OVATION model, magnetic impulse events, Ps6 / Pi3 pulsations.

\section{Introduction: Small-scale impulsive disturbances and GICs}

Space weather caused by the interaction of solar ejecta with the near-Earth environment activates global electromagnetic and plasma processes: intensification of the magnetosphere - ionosphere current systems, energization of ring current and radiation belt particles, enhancing the energetic particle precipitation into the atmosphere, etc. These processes have a potential risk for space and ground technologies. One of the most significant factors of the space weather for terrestrial power transmission lines are geomagnetically induced currents (GICs) due to large 


\section{Olga Kozyreva et al.}

magnitude, rapid temporal changes, dB/dt, of the geomagnetic field B [e.g., Boteler, 2001; Kappenman, 2004]. GICs may be imagined as the result of electric discharge of terrestrial electric potential inhomogeneously distributed along the Earth's surface through a grounded power line. For this reason, GICs are considered as one of five main hazards in the U.S. [Severe Space Weather Events: Understanding Societal and Economic Impacts: 2008]. Therefore, significant efforts and resources of the geophysical community are aimed at MHD modeling of planetary geomagnetic field disturbances during storm/substorms with and their subsequent effect on GICs [Pulkkinen, 2015; Love et al., 2018].

However, the highest risk of GIC may be related not necessarily to global magnetospheric processes characterized by a considerable energy (e.g., yield of typical substorm is of $\sim 10^{14} \mathrm{~J}$ ), but also to more localized and rapid processes [Kataoka and Ngwira, 2016]. The interaction between the solar wind and the magnetosphere can be considered as a source of diverse types of nonstationary processes and perturbations with different spatial and temporal scales. Such localized and fast processes embedded into substorm's evolution seem to be the actual drivers of GIC bursts [Belakhovsky et al., 2019]. The impulsive geomagnetic disturbances that appear in ground-based magnetometer records during nighttime may be associated with substorm onsets and subsequent activations, magnetic impulse events (MIEs) - sporadic perturbation of the geomagnetic field with a duration of $\sim 10 \mathrm{~min}$, intense geomagnetic pulsations Ps6/Pi3 - quasi-periodic series of impulses with duration 10-20 min, and monochromatic Pc5 pulsations (periods of 3-10 min). Though the power of such processes is many orders of magnitude lower than the power of magnetospheric storms and substorms, the associated rapidly varying electromagnetic fields can induce significant GICs [Viljanen, 1998; Apatenkov et al., 2004; Belakhovsky et al., 2018; Yagova et al., 2018].

Rapid changes of the geomagnetic field during substorm onset may occur at different latitudes depending on a type of substorm. Ordinary high latitude substorms emerge at auroral latitudes, but polar substorms may develop beyond the auroral oval [Despirak et al., 2014]. During "polar" substorms all disturbances are concentrated in a narrow latitude region near the polar cap (geomagnetic latitude $\Phi>70^{\circ}$ ), and usually occur under low geomagnetic activity, when the auroral oval is contracted and shifted poleward. During high latitude substorms, a disturbance starts at auroral latitudes, then moves poleward to high geomagnetic latitudes $\left(\Phi>75^{\circ}\right)$ [Mende et al., 1999]. It is not yet clear whether mechanisms of high latitude and polar substorms are the same.

Isolated nighttime magnetic impulsive events (MIEs) observed at auroral zone latitudes have often been associated with substorms, but the occurrence rate and characteristics of MIEs in the high latitude regions are still relatively unknown. Case studies of intense MIE events using magnetometers, together with observations of dynamic auroras from auroral imagers and high-altitude spacecrafts in the nightside magnetosphere, can be found in [Engebretson et al., 2019].

During substorms, the development of MIEs may occur as a quasiperiodic sequence of magnetic pulses, named Ps6/Pi3 pulsations (quasi-periods around 5-20 min) [Kleimenova et al., 2002; Connors et al., 2003]. These irregular quasi-periodic disturbances are accompanied by transient auroral forms. Such specific auroral forms - omega bands, which resemble inverted Greek W, have been known for a long time, but their magnetospheric source and physical mechanism have not been firmly established [Opgenoorth et al., 1983; Amm et al., 2005; Sergeev et al., 2005]. The omega bands are often formed from auroral streamers and have life time up to 10-100 minutes. Omega bands are possibly driven by a series of eastward-drifting (with speed $0.4-2 \mathrm{~km} / \mathrm{s}$ ) pairs of upward and downward field aligned currents with amplitude up to 2MA. Examination of the substorm fine structure from ground magnetometer data, in particular isolated and multiple MIEs, and their magnetospheric context, requires specialized methods, though simple enough for a mass-processing.

This paper presents a study of typical events of nighttime impulsive magnetic disturbances recorded by stations in Fennoscandia and Northern Russia. For a detailed examination of the latitudinal structure of magnetic pulses we applied the technique of magnetic keograms [Kozyreva et al., 2018]. The association of geomagnetic impulsive disturbances with GICs is investigated by measuring the quasi-DC current in power line transformers in the NorthWest Russia. The magnetic keograms are mapped onto the positions of the auroral boundaries in the sector under study derived from the OVATION-prime model. This mapping technique may help to identify the latitudinal location of $\mathrm{dB} / \mathrm{dt}$ enhancements and give a clue as to the responsible physical mechanisms.

\section{Data Set and Event Analysis Technique}

The geomagnetic field 3-components variations $\Delta \mathbf{B}=\{X, Y, Z\}$ were measured by the international array of 
magnetometers, IMAGE (10-sec cadence, see coordinates in Table 1), which is composed of stations in Finland, Russia, Norway, and Sweden [Tanskanen, 2009]. Only stations that form a latitudinal profile along the geomagnetic longitude $\sim 110^{\circ}$ (local noon around 09 UT) have been selected for this study.

The magnetic field variability is characterized by the magnitude of the time derivative

$$
\frac{d B}{d t}=\sqrt{\left(\frac{d x}{d t}\right)^{2}+\left(\frac{d y}{d t}\right)^{2}+\left(\frac{d z}{d t}\right)^{2}}
$$

The vertical, $Z$-component, is also considered, because GICs may be caused either by variations of horizontal magnetic flux (important for linear power lines), or vertical magnetic flux (important for circle-like power lines). However, just a slight difference can be seen between keograms calculated with all magnetic components, and with only horizontal components. Thus, $\mathrm{d} Z / \mathrm{dt}$ produces a noticeable, but not decisive input in the total $\mathrm{d} B / \mathrm{dt}$ power.

To examine the location, latitudinal extent and magnitude of the $\mathrm{dB} / \mathrm{dt}$ enhancements we have applied the technique of magnetic keograms. In a similar way to optical keograms (time, geomagnetic latitude and auroral intensity), the magnetic keogram allows the magnitude of the magnetic field variations, $\mathrm{d} B / \mathrm{dt}$, (measured in $\mathrm{nT} / \mathrm{s}$ ) to be displayed as a function of time (UT) and geomagnetic latitude $(\Phi)$. This allows both the latitudinal location of $\mathrm{d} B / \mathrm{dt}$ bursts and their temporal variations to be examined. The envelopes of $\mathrm{dB} / \mathrm{dt}(\mathrm{t})$ variations at each station have been determined with the Hilbert transform. The use of this transform enables us to monitor a current disturbance magnitude with a high time resolution (1 min). Using the time series of $\mathrm{dB} / \mathrm{dt}(\mathrm{t})$ amplitude from each station along the latitudinal array, the GRIDDATA interpolation function from the IDL package has been applied to construct a $\Phi$-UT array with equidistant spacing (keogram). This function interpolates scattered data values on a plane to a regular grid using the Inverse Distance algorithm and returns a 2D array. The closely-spaced geomagnetic observations along the array can reveal ionospheric current systems of small spatial size (down to $\sim 100 \mathrm{~km}$ ), producing large amplitude and rapidly varying magnetic fields. For some events, the outmost southward or northward stations have been omitted to improve the scaling of a keogram.

As a regional geomagnetic index we use the IMAGE electrojet indicators (EI) with 1-min cadence providing simple estimates of the total eastward and westward currents crossing the magnetometer network (https://space.fmi.fi/image/www/il_index_panel.php). Their definition is similar to that of the standard planetary $\mathrm{AL}, \mathrm{AU}$ and $\mathrm{AE}$ indices, but the EI index characterizes the intensity of auroral electrojets in the region under consideration in this paper.

To reveal how the location of the $\mathrm{dB} / \mathrm{dt}$ bursts are associated with the position of the auroral oval, we use the OVATION-prime (OP) model [Newell et al., 2014]. The OP model is an auroral precipitation model parameterized by solar wind driving, developed using energetic particle measurements from the low-orbiting Defense Meteorological Satellite Program (DMSP) satellite. Distinguishing features of the model include an optimized solar wind-magnetosphere coupling function which predicts auroral power significantly better than any interplanetary parameter or geomagnetic index. The model separates aurora into categories, and provides separate parameter fits for different $\Phi /$ MLT (magnetic local time) bins, thus permitting each type of aurora and each location to have different responses to season and solar wind input. Here we concentrate on the main types of electron aurorae: discrete monoenergetic aurorae, and broadband diffuse aurorae. The data on Alfvenic aurora are sparse. Diffuse aurora is primarily caused by the precipitation of energetic electrons $(0.1-30 \mathrm{keV})$ over a broad latitude range. Although it is generally not visible to the naked eye, the diffuse auroral precipitation provides the main energy source for the high-latitude upper atmosphere [Newell et al., 2009]. The discrete aurora at higher latitudes is dominated by monoenergetic soft electron precipitation $(0.1-1 \mathrm{keV})$. In this paper, the most poleward auroral boundary is used as a proxy for the ionospheric footprint of the open closed field line boundary (OCB). These auroral boundaries have been preliminary identified with the use of the OP model before being superposed onto the magnetic keogram. The monoenergetic aurora are marked by dotted lines, and diffuse aurora correspond to dashed lines, their equatorward and poleward boundaries are shown in red and blue, correspondingly.

We compare the fine structure of substorms with data from the system to monitor the impact of GICs on power lines deployed in the Kola Peninsula by the Polar Geophysical Institute and the Center for Northern Energetics [Sakharov et al., 2007]. We use the data from the terminal station Vykhodnoi (VKH) at the $330 \mathrm{kV}$ power line located at $\Phi \sim 65^{\circ}$ (Table 1). The station measures, with a 1 min sampling rate, a quasi-DC current in the dead-grounded neutral of a transformer in the power line. This measured current is proportional to an induced GIC in the transmission line. 
Olga Kozyreva et al.

\begin{tabular}{ccccccc} 
Station & Code & $\begin{array}{c}\text { Geographic } \\
\text { Latitude }\end{array}$ & $\begin{array}{c}\text { Geographic } \\
\text { Longitude }\end{array}$ & $\begin{array}{c}\text { CGM } \\
\text { Latitude }\end{array}$ & $\begin{array}{c}\text { CGM } \\
\text { Longitude }\end{array}$ & Network \\
Ny Alesund & NAL & 78.92 & 11.95 & 76.1 & 112.3 & IMAGE \\
\hline Longyearbyen & LYR & 78.20 & 15.83 & 75.1 & 113.0 & IMAGE \\
\hline Hornsund & HOR & 76.97 & 15.47 & 74.0 & 110.5 & IMAGE \\
\hline Hopen Island & HOP & 76.51 & 25.01 & 72.9 & 115.9 & IMAGE \\
\hline Bear Island & BJN & 74.50 & 19.20 & 71.3 & 108.7 & IMAGE \\
\hline Nordkapp & NOR & 71.09 & 25.79 & 67.8 & 109.0 & IMAGE \\
\hline Sørøya & SOR & 70.54 & 22.22 & 67.2 & 106.7 & IMAGE \\
\hline Kevo & KEV & 69.76 & 27.01 & 66.2 & 109.7 & IMAGE \\
\hline Masi & MAS & 69.46 & 23.70 & 66.1 & 106.9 & IMAGE \\
\hline Kilpisjarvi & KIL & 69.06 & 20.74 & 65.9 & 104.5 & IMAGE \\
\hline Ivalo & IVA & 68.70 & 27.30 & 65.0 & 109.8 & IMAGE \\
\hline Sodankyla & SOD & 67.37 & 26.63 & 63.8 & 107.7 & IMAGE \\
\hline Pello & PEL & 66.90 & 24.08 & 63.5 & 105.4 & IMAGE \\
\hline Oulu & OUJ & 64.52 & 27.23 & 60.9 & 106.5 & IMAGE \\
\hline Hankasalmi & HAN & 62.30 & 26.65 & 58.6 & 105.0 & IMAGE \\
\hline Nurmijarvi & NUR & 60.50 & 24.65 & 56.6 & 103.0 & IMAGE \\
\hline Vykhodnoi & VKH & 68.83 & 33.08 & 65.5 & 112.7 & GIC \\
\hline
\end{tabular}

Table 1. Magnetic and GIC stations

\section{Occurrence of impulsive geomagnetic disturbances and GICs}

In this paper we present examples of several types of fast geomagnetic disturbances that may cause bursts of GICs of around 10 Amperes and more: onsets of polar and auroral substorms, MIEs, Ps6 irregular pulsations, and monochromatic Pc5 pulsations. For some type of industrial transformers, a DC current of even several amperes may be sufficient to shift the transformer operations from a linear response to a non-linear regime [Hapgood, 2012]. Here we present typical events from an extensive list compiled upon analysis of 2015 data on GIC bursts caused by various space weather disturbances.

\subsection{Auroral substorm onset on 2015/03/17}

On 2015/03/17 a substorm, with a rapid onset starting at 2310 UT, developed during a strong magnetic storm (minimum SYM-H index of -230 nT). This substorm itself occurred about 18 hours after the sudden commencement of the larger geomagnetic storm. During a gradual increase of geomagnetic activity, the EI index reached a maximum of $\sim 1600 \mathrm{nT}$ (Figure 2a, top panel of time series). Figure 1a shows the $X, Y$ and $Z$ components (top panels, going from left to right) of the ground magnetometer data from 10 stations of the IMAGE array 
over a geomagnetic latitudinal range from $\Phi \sim 61^{\circ} \mathrm{N}$ to $\sim 71^{\circ} \mathrm{N}$. In the $X$ component, a poleward moving magnetic bay can be seen (Figure 1a, left-hand panel) starting at OUJ at $\sim 2305$ UT and reaching BJN at $\sim 2320$ UT. In the $Y$ and $Z$ components (Figure 1a, middle and right-hand panels), the onset is revealed as an intense localized impulse with a duration of $\sim 20$ minutes, reaching a maximum amplitude of $\sim 1000 \mathrm{nT}$ around $\Phi \sim 66^{\circ} \mathrm{N}-67^{\circ} \mathrm{N}$ (KEV-NOR). The lower panels in Figure 1a indicate the magnetic variability $(\mathrm{d} \boldsymbol{B} / \mathrm{dt})$ for each of the corresponding magnetic components (that is $\mathrm{d} X / \mathrm{dt}, \mathrm{d} Y / \mathrm{dt}$, and $\mathrm{d} Z / \mathrm{dt}$ ) and magnetometer stations. The largest magnetic field variability $\mathrm{d} Z / \mathrm{dt} \sim 22 \mathrm{nT} / \mathrm{s}$ is reached in the $Z$ component at the latitude $\sim 68^{\circ} \mathrm{N}$ (NOR), whereas peak-to-peak amplitudes of $\mathrm{d} X / \mathrm{dt}$ and $\mathrm{d} Y / \mathrm{dt}$ are somewhat weaker, $\sim 18 \mathrm{nT} / \mathrm{s}$.

The magnetic keogram, shown in the top panel of Figure $1 \mathrm{~b}$, shows the latitudinal location of the $\mathrm{dB} / \mathrm{dt}$ enhancements and their evolution with time. It evidently shows the poleward movement of the burst of the magnetic field variability across the auroral boundaries determined with the OP model. Intense fluctuations originate near the equatorward boundary of diffuse aurora (shown by the red dashed line), and then expand rapidly poleward reaching the in a poleward boundary of monoenergetic aurora (shown by the blue dotted line) in 21 minutes ( 2305-2315 UT).

The bottom panels of Figure $1 \mathrm{~b}$ show a time series of the EI index (top panel), the $X$ component of the ground magnetometer data from 4 stations (middle panel) and the measured DC current in the ground transformer (in Amps) (bottom panel). A largest burst of GIC with magnitude J>50 A is recorded not during the substorm onset at $\sim 2305 \mathrm{UT}$, but when the region of intense $\mathrm{d} B / \mathrm{dt}$ crosses the latitude of GIC station VKH at $2313 \mathrm{UT}$.

\subsection{Polar substorm onset on 2015/03/24}

On 2015/03/24 an isolated polar substorm started at 1630 UT. In contrast to the auroral substorm of the previous example, the maximum magnetic bay of this substorm occurs at very high latitudes $74^{\circ} \mathrm{N}-75^{\circ} \mathrm{N}$ (LYR-HOR). Figure 2a (which has the same format as Figure 1a, although with a larger latitudinal range) shows a poleward propagation of the disturbance in the X component (Figure 2a, top, left-hand panel), whereas in the $Y$ component irregular disturbances can be seen.

The magnetic keogram shown in Figure 2a indicates the same poleward motion of the $d B / d t$ enhancements as the previous example and is also consistent with poleward motion of the magnetic bay observed in the $X$ component. The latitudinal motion of the largest $\mathrm{d} B / \mathrm{dt}$ enhancements in this example extends from the equatorward monoenergetic auroral boundary (red dotted line) to poleward of its poleward boundary (blue dotted line). Despite the high magnitude of this substorm (indicated by the EI index in the top panel of time series at the bottom of Figure $2 \mathrm{~b}$ ) of $\sim 1000 \mathrm{nT}$, the observed GIC is significantly smaller than the previous example with J 8 A (shown in the bottom time series in Figure $2 \mathrm{~b}$ ). The reason is that the "epicenter" of $\mathrm{dB} / \mathrm{dt}$ enhancement is at a latitude that is $\sim 10^{\circ}$ higher than that of the GIC station located at $65^{\circ}$.

\subsection{Isolated nightside MIE on 2015/09/20}

On 2015/09/20 an isolated magnetic pulse was observed across a wide range of latitudes $\Phi \sim 65^{\circ} \mathrm{N}-67^{\circ} \mathrm{N}$ (MUONOR) at $\sim 2035$ UT. The pulse had a duration of $\sim 15$ mins and an amplitude, in the $X$ component, of $\sim 200$ nT (left-hand top panel of Figure 3a). Evidence of isolated pulse can be seen in the $Y$ and $Z$ components. The event is also recorded in the EI index as a sudden increase of $\sim 150 \mathrm{nT}$, up to a value of $300 \mathrm{nT}$ (Figure 3b). The largest magnetic field variability, $\sim 6 \mathrm{nT} / \mathrm{s}$, is observed at latitudes $\sim 67^{\circ} \mathrm{N}$ in the $Y$ component (Figure 3a, bottom middle panel). This event is similar to other investigations of MIEs that have been studied with data from stations in Northern Canada [Engebretson et al., 2019]. A more detailed examination of the IMAGE data indicates that this magnetic pulse could be associated with a weak substorm onset at higher latitudes $\left(\Phi>66^{\circ}\right)$.

In comparison to the previous examples, where a distinct poleward propagation of the $\mathrm{d} B / \mathrm{dt}$ enhancements were observed, in this event the $\mathrm{d} B / \mathrm{dt}$ enhancements start simultaneously across $\sim 6^{\circ}$, from $64^{\circ} \mathrm{N}$ to $70^{\circ} \mathrm{N}$ as shown in the top panel of Figure $3 \mathrm{~b}$. In addition, the maximum in the $\mathrm{dB} / \mathrm{dt}$ enhancements are concentrated around the poleward boundary of the diffuse aurora (blue dashed line) before moving slightly equatorward.

This impulse causes a burst of GIC that reaches about 5 A (bottom panel, Figure 3b). 

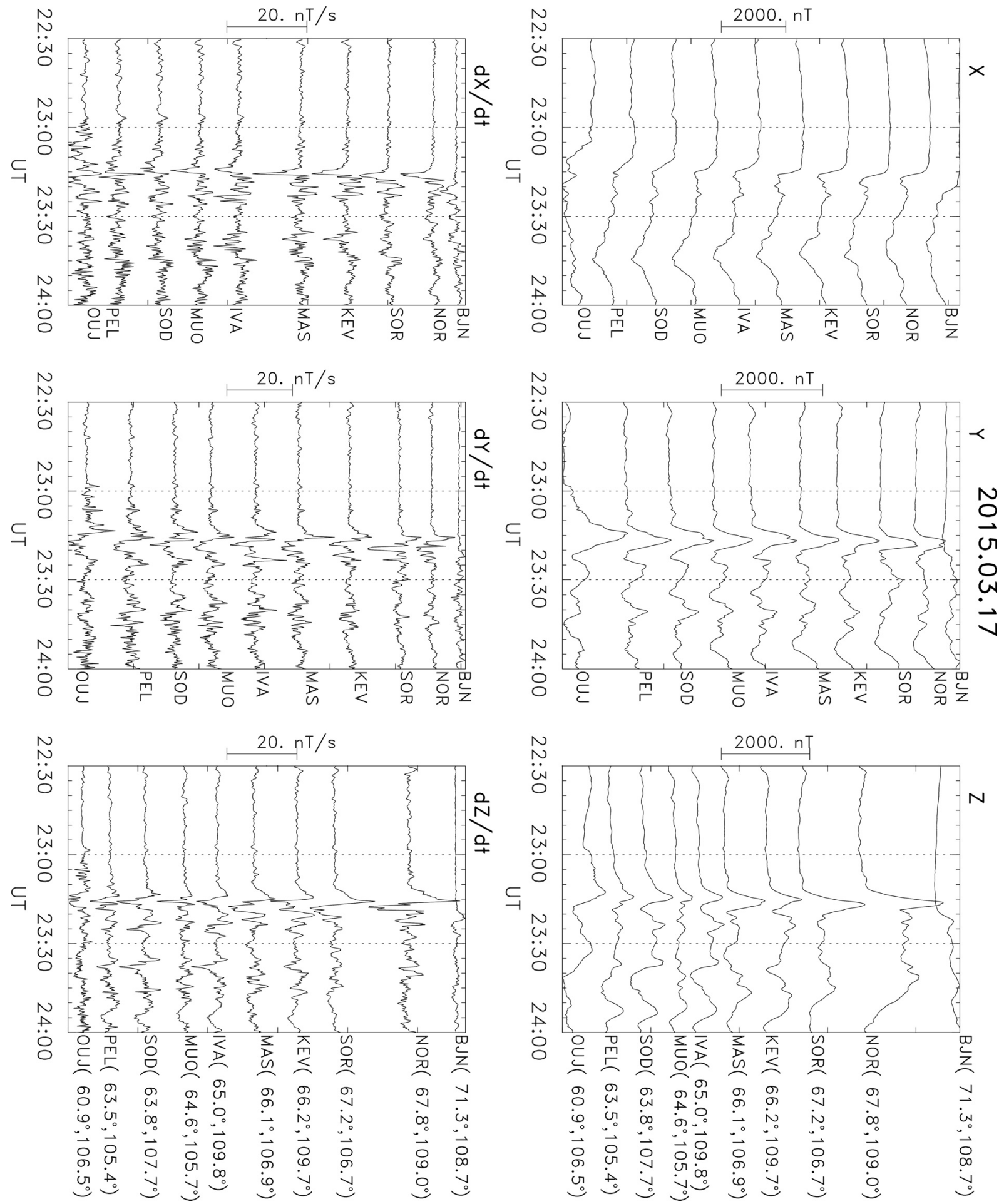

Figure 1a. Auroral substorm occurred on 2015/03/17, 2230-2400 UT: magnetograms of $X, Y$, and $Z$ components (upper panels), and their time derivatives $\mathrm{d} X / \mathrm{dt}, \mathrm{d} Y / \mathrm{dt} /$ and $\mathrm{d} Z / \mathrm{dt}$ (bottom panels). The scale (in nT) for the magnetograms are shown on the left-hand side of each panel, with a line representing a magnitude of $2000 \mathrm{nT}$. The scale (in nT/s) for the magnetic variability plots are shown on the left-hand side of each panel, with a line representing a magnitude of $20 \mathrm{nT} / \mathrm{s}$. The codes and geomagnetic coordinates of the stations are shown on the right-hand side of the panels. 

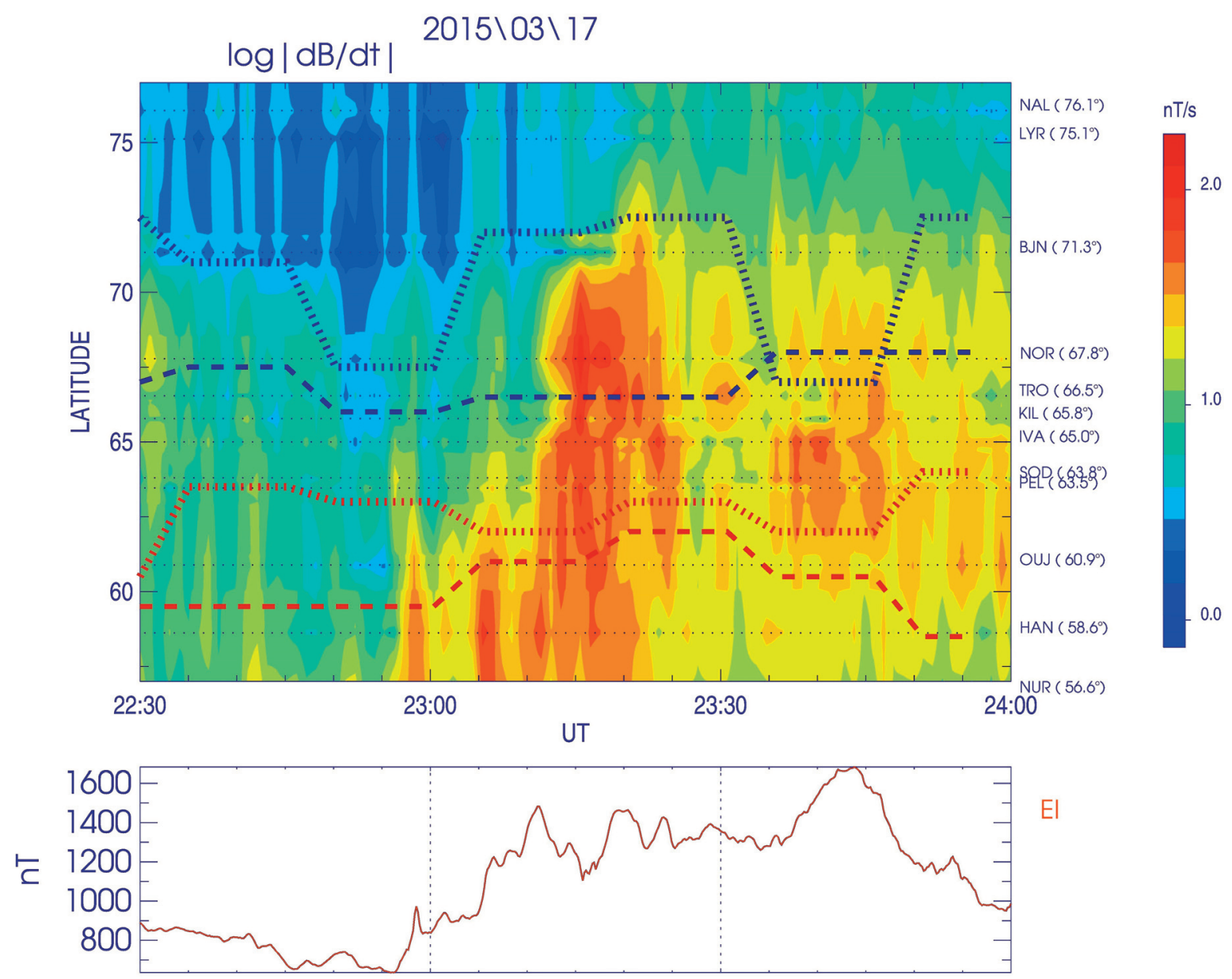

$\mathrm{El}$
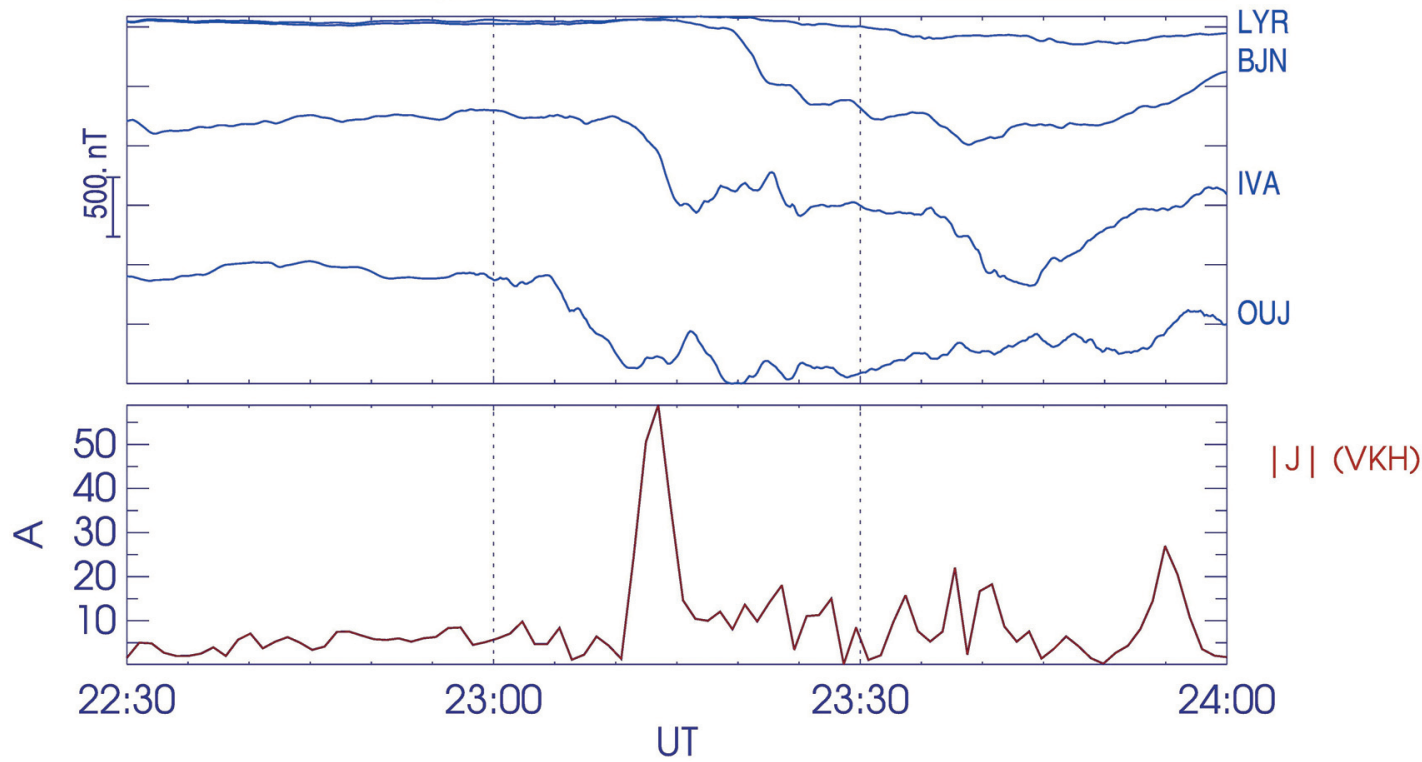

Figure 1b. Keogram of $|\mathrm{dB} / \mathrm{dt}|$ (log scale) with superposed auroral boundaries derived from the OP model for the auroral substorm occurred on 2015/03/17, 2230-2400 UT: dotted lines for the monoenergetic aurora, and dashed lines for the diffuse aurora; their equatorward and poleward boundaries are shown in red and blue, correspondingly. The plot also shows the EI index (second panel), magnetograms of the X component from several stations (third panel), and magnitude of GIC IJ| at VKH (bottom panel) at latitude $65^{\circ} \mathrm{N}$. 
Olga Kozyreva et al.
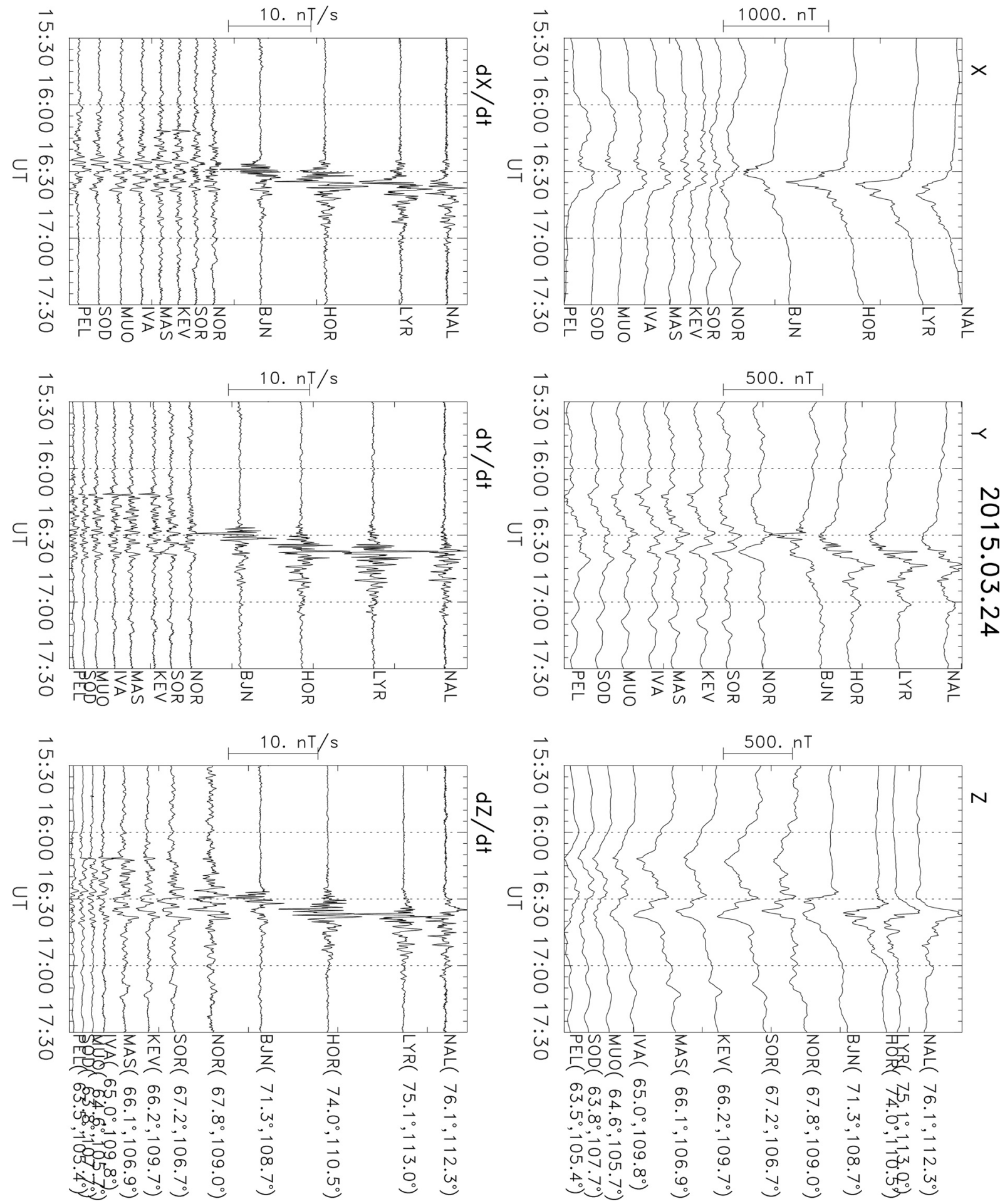

Figure 2a. Polar substorm occurred on 2015/03/24, 1530-1730 UT: magnetograms and $d B / d t$ variations in the same format as Figure 1a. 

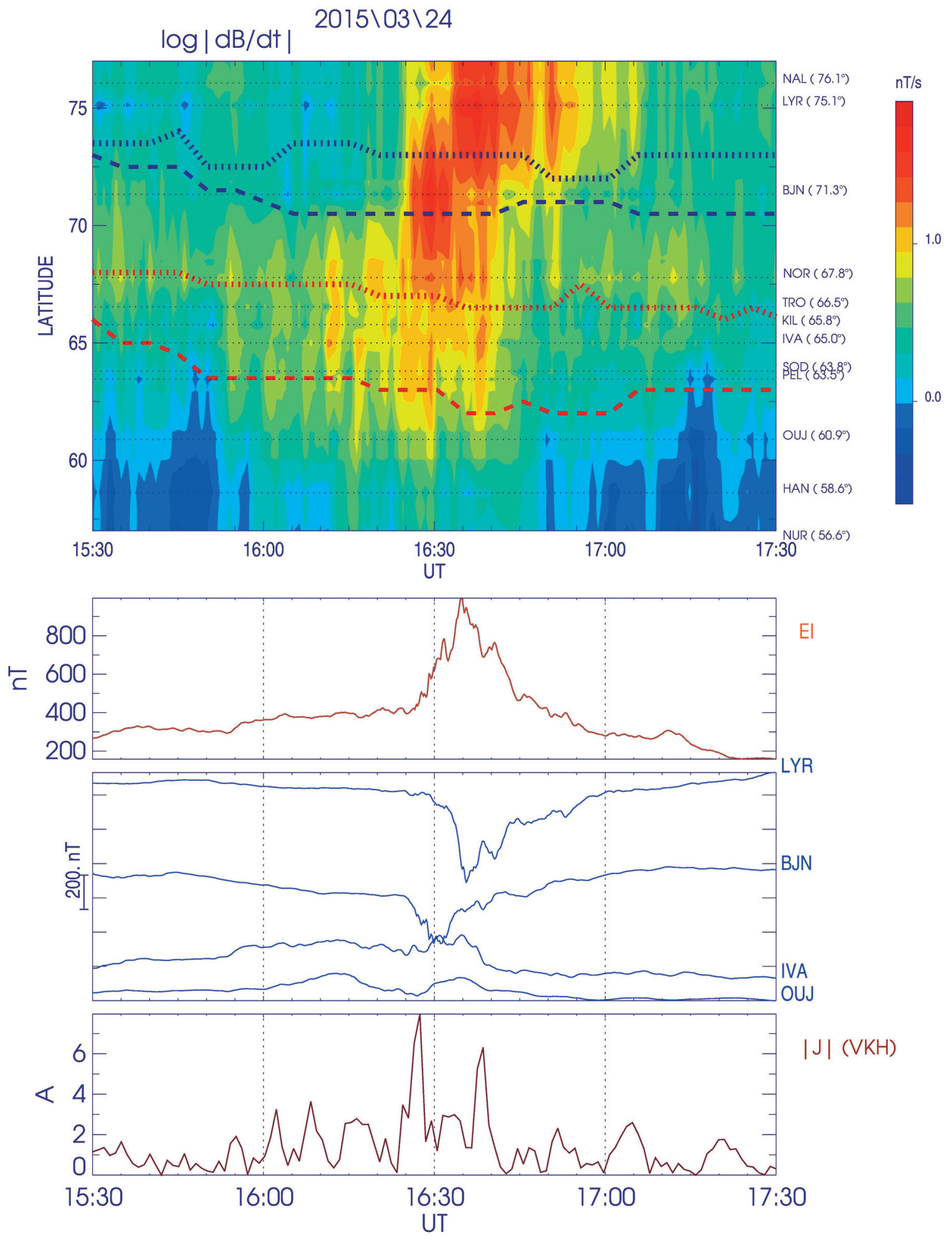

Figure 2b. Keogram of $|\mathrm{d} B / \mathrm{dt}|$ (log scale) with superposed auroral boundaries derived from the OP model for the polar substorm occurred on 2015/03/24, 1530-1730 UT (upper panel), the EI index (second panel), magnetograms of $\mathrm{X}$-component from several stations (third panel), and magnitude of GIC IJ| at VKH (bottom panel). 
Olga Kozyreva et al.
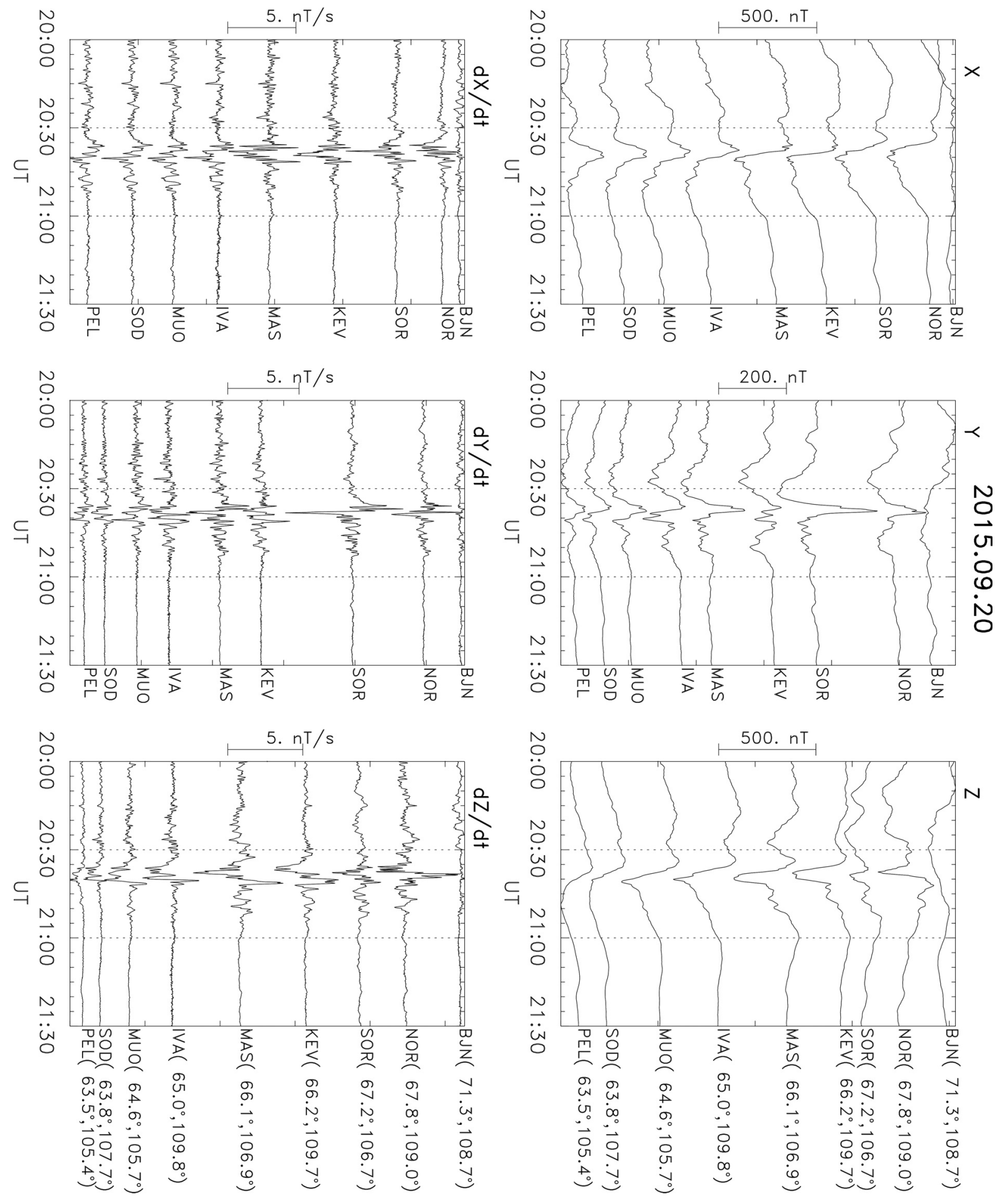

Figure 3a. Isolated MIE occurred on 2015/09/20, 2000-2130 UT: magnetograms and dB/dt variations in the same format as Figure 1a. 
Substorm fine structure and GICs
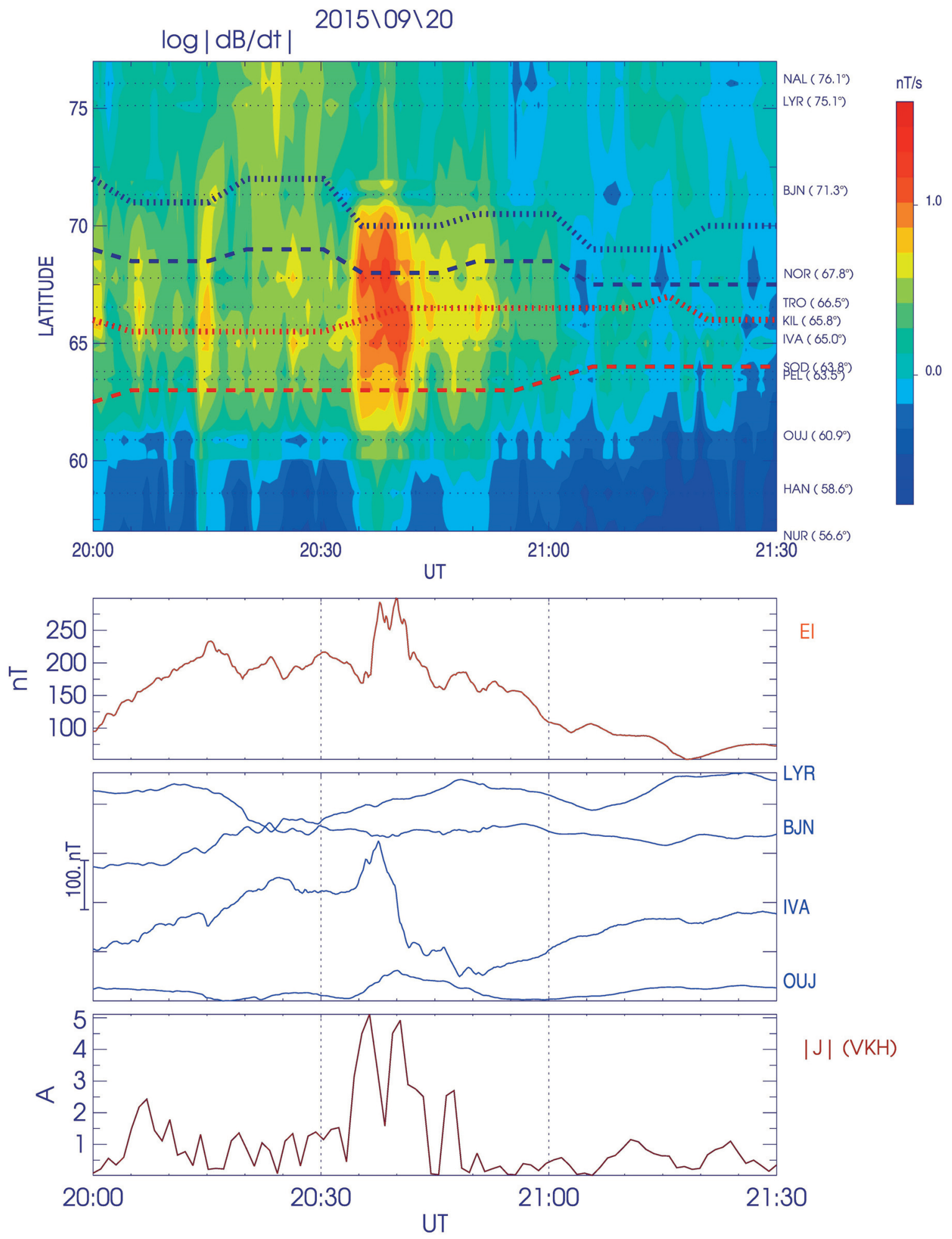

Figure 3b. Keogram of $|\mathrm{d} B / \mathrm{dt}|$ (log scale) with superposed auroral boundaries derived from the OP model for the isolated MIE on 2015/09/20, 2000-2130 UT (upper panel), the EI index (second panel), magnetograms of X-component from several characteristic stations (third panel), and magnitude of GIC IJ| at VKH (bottom panel). 
Olga Kozyreva et al.
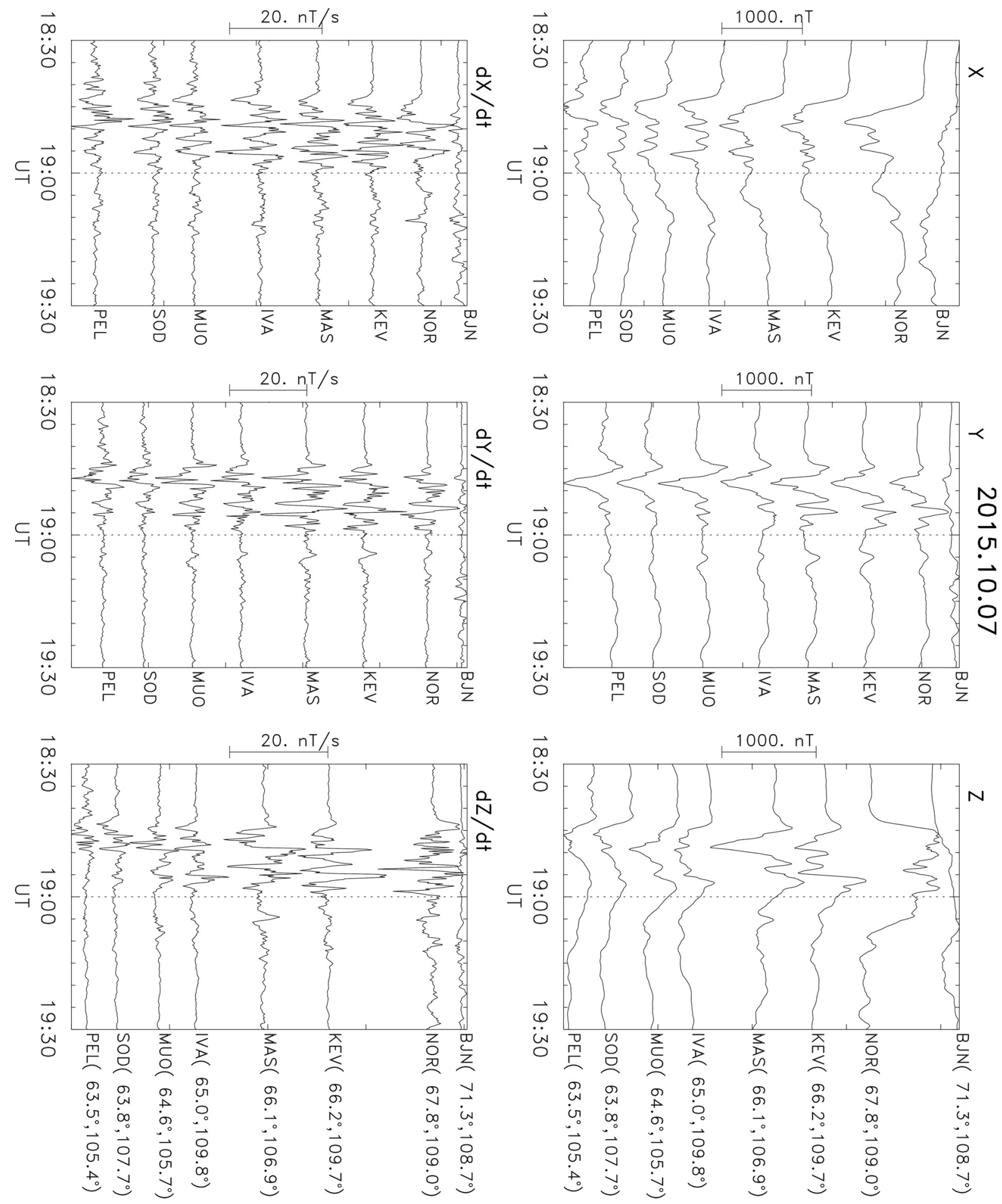

Figure 4a. Series of MIEs (Ps6 pulsations) on 2015/10/07, 1830-1930 UT: magnetograms and dB/dt variations in the same format as Figure 1a. 

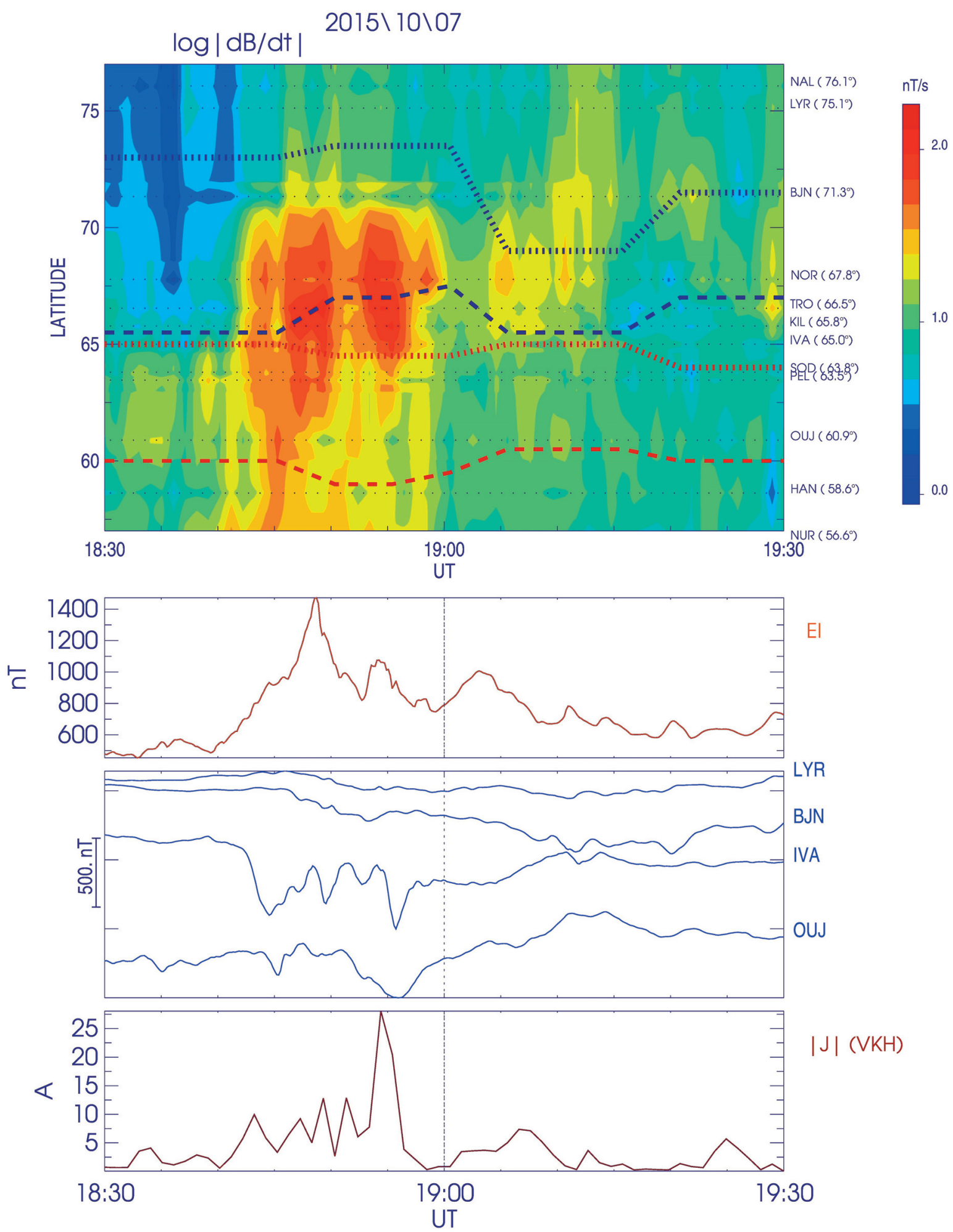

Figure 4b. Keogram of $|\mathrm{d} B / \mathrm{dt}|$ (log scale) with superposed auroral boundaries derived from the OP model for the Ps6 pulsations occurred on 2015/10/07, 1830-1930 UT (upper panel), the EI index (second panel), magnetograms of the $X$ component from several characteristic stations (third panel), and magnitude of GIC IJ| at VKH (bottom panel). 

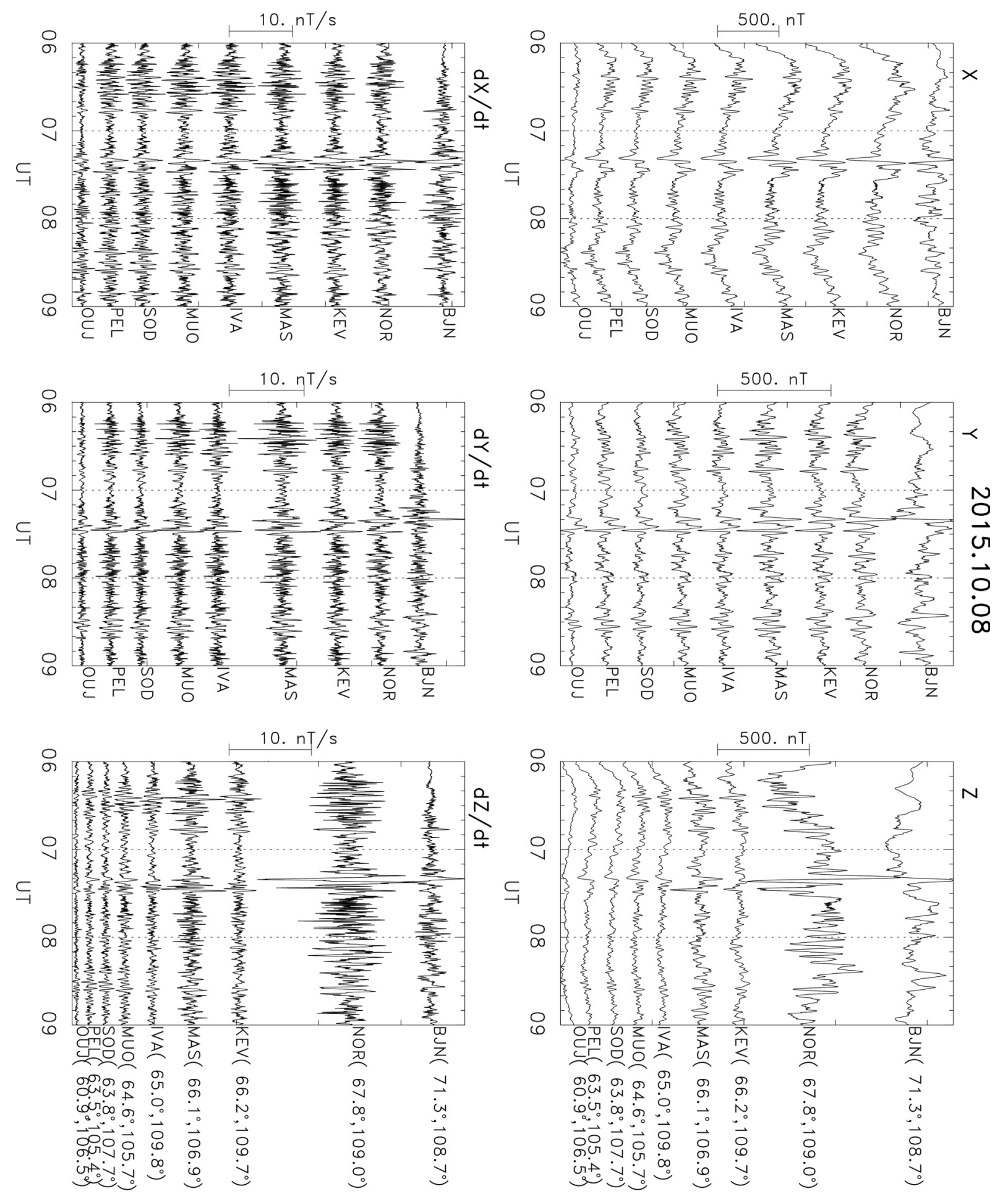

Figure 5a. Pc5 pulsations occurred on 2015/10/08, 06-09 UT: magnetograms and dB/dt variations in the same format as Figure 1a. 

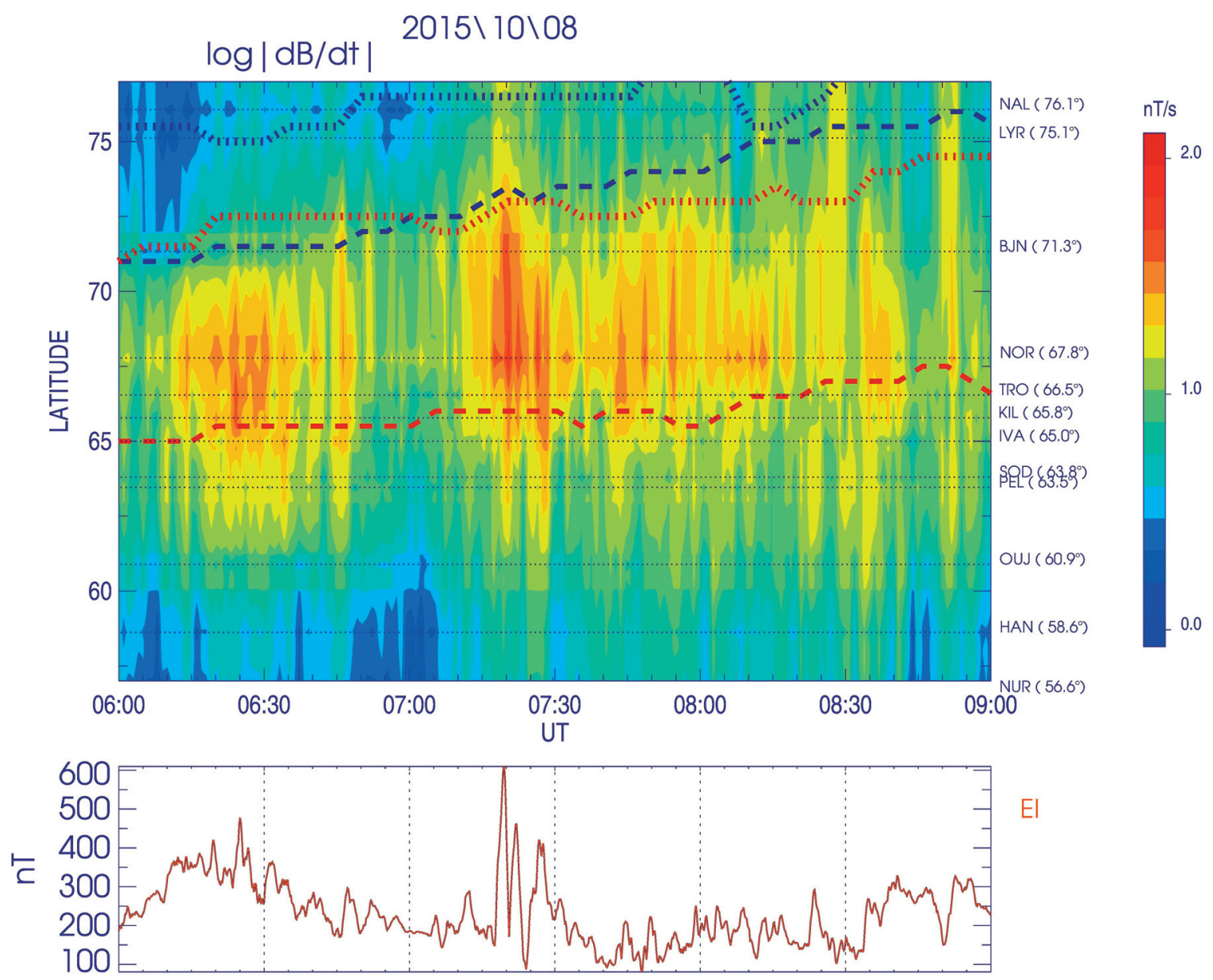

El
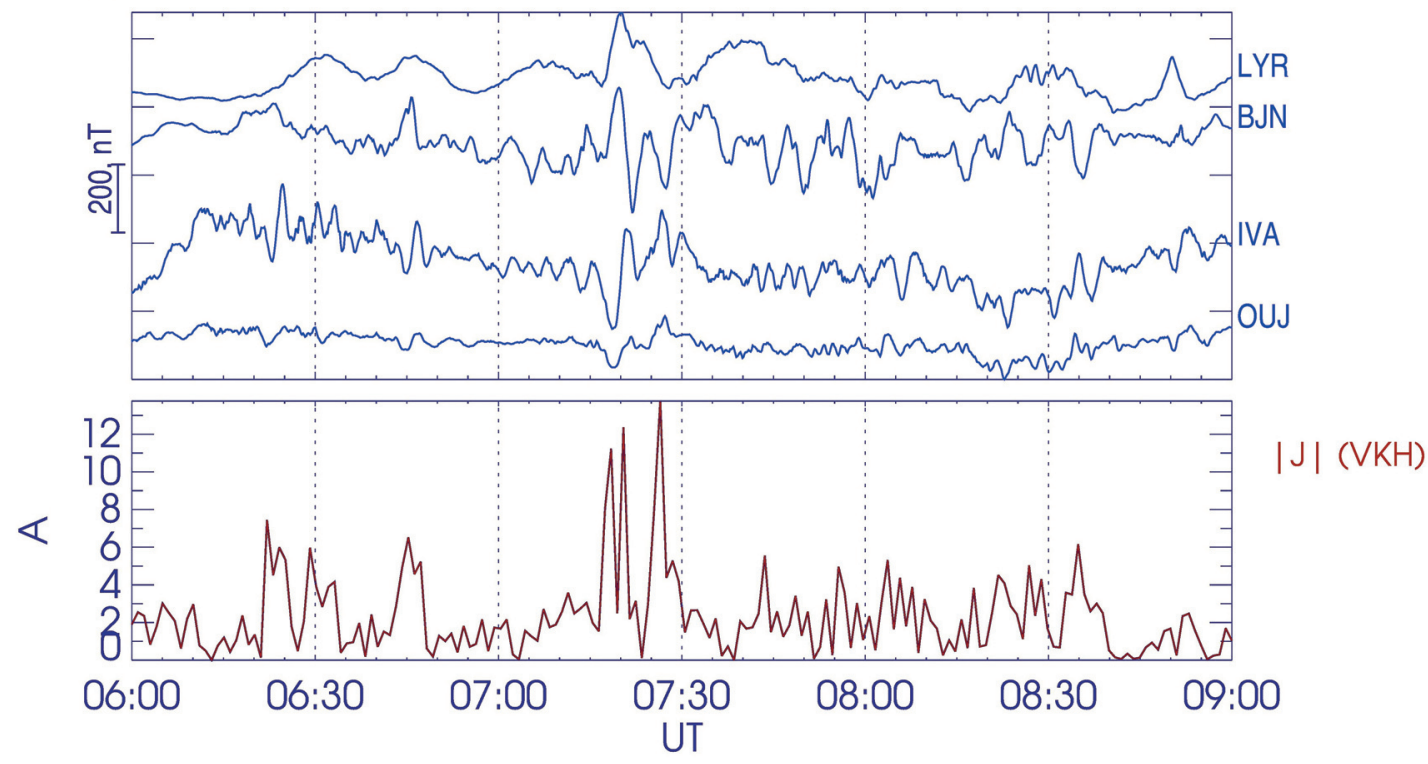

Figure 5b. Keogram of $|\mathrm{d} B / \mathrm{dt}|$ (log scale) with superposed auroral boundaries derived from the OP model occurred on 2015/10/08, 06-09 UT (upper panel), the EI index (second panel), magnetograms of the $X$ component from several stations (third panel), and magnitude of GIC IJI at VKH (bottom panel). 


\section{Olga Kozyreva et al.}

\subsection{Series of nightside MIEs: Ps6/Pi3 pulsations on 2015/10/07}

On 2015/10/07 a substorm with a rapid onset was observed to start at 1845 UT. A maximum deviation in the $X$ component of $\sim 1000 \mathrm{nT}$ was observed in the NOR magnetometer at $\sim 67^{\circ} \mathrm{N}$ (left-hand top panel in Figure $4 \mathrm{a}$ ). In comparison to the substorm event presented in section 3.1 (which also had a similar magnitude and occurred at a similar latitude) this event has a series of intense, irregular Ps6 pulsations (quasi-periodic sequence of MIEs with duration 3-7 min) which occurred after the expansion phase from 1845-1900 UT. These pulsations are not harmonic oscillations, but a series of non-linear magnetic pulses with steep fronts and are most evident in the $Y$ component (Figure 4a, top middle panel). The corresponding magnetic variability, $\mathrm{dB} / \mathrm{dt}$, is also the largest in the $Y$ component (bottom middle panel in Figure 4a) with values up to $\sim 20 \mathrm{nT} / \mathrm{s}$. Whilst there is evidence of the substorm onset in the EI index, with a peak value of $\sim 1400 \mathrm{nT}$ (top time series panel in Figure 4b), the Ps6 pulsations themselves are not captured. Also, as shown in the bottom panel of Figure 4b, it is the Ps6 pulsations that have the greatest influence on the magnitude of the GICs, creating associated quasi-periodic enhancements from 1845 UT.

These Ps6 pulsations cause quasi-periodic enhancements of GIC. The GIC reaches maxima higher than $25 \mathrm{~A}$ not during the substorm onset, but during one of the subsequent pulses (Figure $4 \mathrm{~b}$ ). The epicenter of $\mathrm{dB} / \mathrm{dt}$ fluctuations is near the equatorward monoenergetic auroral boundary predicted by the OP model.

\subsection{Pc5 pulsations on $2015 / 10 / 08$}

In the early morning hours (06-09 UT) of 2015/10/08, quasi-monochromatic Pc5 pulsations with periods $\sim 3-5$ min can be observed (top row of panels in Figure 5a). The amplitudes of $X$ and $Y$ components are comparable (peak-topeak amplitudes up to $\sim 200 \mathrm{nT}$ ). The $Z$ component has larger amplitude variations (up to $\sim 600 \mathrm{nT}$ peak to peak), although the enhancements are more localized in latitude. The same relationships hold for the field variability: $\mathrm{dZ} / \mathrm{dt}$ is up to $\sim 15 \mathrm{nT} / \mathrm{s}$ and at least 2 times bigger than that of $\mathrm{d} X / \mathrm{dt}$ and $\mathrm{d} Y / \mathrm{dt}$.

Since there is no substorm activity associated with this event, the EI index remains fairly low ( $200 \mathrm{nT})$ during the event, peaking to $\sim 600 \mathrm{nT}$ at $\sim 0720$ UT (top panel of time series in Figure $5 \mathrm{~b}$ ). The magnetic keogram (Figure $5 \mathrm{~b}$, top panel) shows the pulsations as a series of $\mathrm{dB} / \mathrm{dt}$ enhancements, centered at around $67^{\circ}$ latitude. There is very little latitudinal motion in the enhancements, again reflecting that these pulsations are not associated with any larger scale substorm activity, with the epicenter of the $\mathrm{d} B / \mathrm{dt}$ remaining within the diffuse auroral oval (top panel of Figure $5 b$ ). Due to the large magnetic variability associated with the Pc5 pulsations, the GIC magnitude is significantly elevated, and reaches about J 12 A (bottom panel of Figure 5b).

\section{Discussion}

A coordinated analysis of GICs (measured using a dead-grounded neutral of a transformer in a power line) and ground magnetometer data from the IMAGE array has confirmed that short duration isolated enhancements in the electric grid may arise from impulsive magnetic disturbances. The GIC data has indicated that it is the local $\mathrm{dB} / \mathrm{dt}$ enhancements associated with smaller scale structures during a substorm that is important. Such small scale structures cannot be measured by the use of larger geomagnetic indices which rely on data sources across a larger range of latitudes. Thus, the use of GIC measurements could be a valuable tool for use in geophysical research [Guillon et al., 2016]. Some of the $\mathrm{d} B / \mathrm{dt}$ bursts exceed the commonly used threshold of 5 nT/s for potential damage to the electrical grid [e.g., Engebretson et al., 2019]. As a reference, the Hydro Quebec collapse was associated with a storm-related $\mathrm{dB} / \mathrm{dt}$ value of $\sim 8 \mathrm{nT} / \mathrm{s}$ [Bolduc, 2002]. In this paper we presented examples of different impulsive disturbances and their associated $\mathrm{dB} / \mathrm{dt}$ enhancements and resulting GIC. The data shows that, in our examples, the auroral substorm (case 3.1 in the above section) induced the largest response in the GICs. The most intense GIC (few tens of A) has been observed when the poleward moving intensification of the magnetic field variability crossed the latitude of power line. Polar substorms (case 3.2 in the above section) originating at much higher latitudes in comparison to the location of the power line are less effective in GIC excitation, with enhancements of J 6 A only. Isolated nightside MIEs (case 3.3 in the above section) occurring after onset are also effective in the excitation of GICs (J 10 A), but they are relatively rare. 
At the same time, a quasi-periodic series of magnetic pulses is a typical feature of substorms, known as Ps6 or Pi3 pulsations. Quasi-periodic Ps6 pulsations have turned out to be very effective in the excitation of GICs. The recorded disturbances are about J 20 A and even higher (case 3.4 in the above section). Indeed, the statistical diurnal variations of the intensity of GICs are known to have an additional maximum, besides the midnight maximum associated with substorm onset, in the early morning hours - the typical region of Pi3/Ps6 pulsation occurrence [Vorobev et al., 2019]. Monochromatic Pc5 pulsations are also capable of inducing noticeable GICs, up to J 13 A (case 3.5 in the above section).

The events with the largest magnetic variability $(\mathrm{dB} / \mathrm{dt})$ are not co-incident with those events with the largest magnetic deviations in a particular component of the magnetic field (generally the X or Y component) [Kozyreva et al., 2018]. In addition to being linked to GIC enhancements with different amplitudes, different types of impulsive geomagnetic disturbances have been found to have a different location of the $\mathrm{dB} / \mathrm{dt}$ epicenter in respect to the auroral boundaries. Observations from an array of ground-based magnetometers have provided evidence that many intense nighttime MIEs occur at the poleward edge of the auroral zone [Engebretson et al., 2019]. The epicenter of $\mathrm{dB} / \mathrm{dt}$ fluctuations associated with Ps6 pulsations has been found to be predominantly near the equatorward monoenergetic auroral boundary. The effective latitudinal range of $\mathrm{dB} / \mathrm{dt}$ associated with isolated and multiple MIEs studied here is of $\sim 3^{\circ}-5^{\circ}$.

Our observations support results found by other authors using different data and at different latitudes. Ngwira et al. [2018] found that many extreme nighttime dB/dt variations were associated with a poleward expanding discrete aurora passing over magnetometer sites. In the two events studied, intense $\mathrm{dB} / \mathrm{dt}$ events appeared near the poleward edge of the auroral zone and moved poleward as the auroral oval expanded poleward. This location is consistent with the satellite observations of Keiling et al. [2000] who showed that the intense field-aligned Poynting flux of Alfvenic disturbances occurs at the poleward edge of the aurora. Our observations, although based on a different database, support this conjecture.

In this study we have tried to elaborate a way to find a spatial association between $\mathrm{dB} / \mathrm{dt}$ enhancements and the position of the auroral boundaries. In a similar way, Vorobiev et al. [2018] compared the mutual locations of the westward ionospheric electrojet (using the IMAGE-based profile http://space.fmi.fi/MIRACLE) and discrete aurora precipitation boundaries (using the Auroral Precipitation Model (APM) http://apm.pgia.ru). The empirical APM, similar to the OP model, is based on the data of DMSP observations, but it is parameterized by geomagnetic indices. A comparison of the location of these boundaries with observations of GICs in the NorthWest region of Russia showed that the equatorward boundary of auroral oval precipitation can be a good proxy for the westward electrojet equatorward boundary in the near midnight MLT sector. The GIC intensity reached its maximum during the period when the precipitation equatorial boundary was located in the zenith of a GIC observation point. Vorobiev et al. [2018] claimed that the most significant source of the GICs is the westward electrojet.

In this paper we suggest that an actual driver of GICs is not the auroral electrojet, but isolated or multiple, impulsive, short-lived ( 10 min time scale) disturbances embedded in it. The comparison of the magnetic variability keograms with the auroral boundaries determined from the OP model has shown the following

- during substorm onset the largest variability is concentrated in the region of diffuse aurora;

- for isolated MIE and quasi-periodic series of pulses (Ps6 pulsations) the largest variability corresponds to the equatorward boundary of the monoenergetic aurora;

- for Pc5 pulsations the largest variability is in the region of diffuse aurora. The latter observations agree with the statistical results of Martines-Bedenko et al. [2018].

However, these results should be considered with some caution, because they are based not on actual auroral or satellite observations, but on the IMF-controlled OP model.

The mechanism of quasi-periodic Ps6 disturbances has not been firmly established. Their periodicity of 5$20 \mathrm{~min}$ is larger than typical field line eigenfrequencies at auroral latitudes (3-10 min). Ps6 magnetic pulsations are often associated with the auroral omega bands forms which typically occur at the poleward edge of the diffuse auroral region and are characterized by a series of North-South aligned protrusions. The substorm activations are typically associated with an activation of the most poleward arc system (called Poleward Boundary Intensifications - PBI) followed by the equatorward ejection of North-South aligned auroral forms. A quasi-periodic sequence of these auroral forms can excite Ps6 magnetic pulsations. The nighttime, isolated 


\section{Olga Kozyreva et al.}

MIEs observed during substorms can occur in association with some magnetotail transient phenomena (e.g., isolated Bursty Bulk Flows - BBF). It has been suggested that it is very likely that PBI auroral events are ionospheric manifestation of multiple BBFs in the tail [Henderson et al., 2002], and they eventually could be a driver of Ps6 pulsations.

The observed ground magnetic effect can be caused by the fast movement of localized current systems in the longitudinal direction in the ionosphere. The Ps6/Pi3 pulsations and associated auroral omega bands are related to intense field-aligned currents which, even with constant amplitude, may provide large ground variations of the geomagnetic field due to the rapid source motion. The magnetic field variations caused by a localized ionospheric current system with lateral gradient scale $a$ and propagating with velocity $V$ along the ionosphere may be estimated as

$$
\frac{d B}{d t}=\frac{\partial B}{\partial t}+(V \nabla) B
$$

For typical values of $V \sim 2 \mathrm{~km} / \mathrm{s}$ and $a \sim 20 \mathrm{~km}$, the expected magnetic variability due to the ionospheric structure motion is about $\frac{d B}{d t} \sim V B / a \sim 10 \mathrm{nT} / \mathrm{s}$. This estimate matches typical magnitudes of $\mathrm{d} B / \mathrm{dt}$ recorded during intense Ps6 events. Consequently, the Ps6 pulsations are able to produce intense GICs which are potentially dangerous for the man-made technological networks. In analogy to terrestrial weather, these intense localized disturbances on short timescales are more like geomagnetic "strokes" during the magnetospheric "thunderstorm". While global MHD modeling of the magnetospheric response to interplanetary space weather is capable of predicting the magnetospheric "thunderstorm", the occurrence and intensity of geomagnetic "strokes" is very difficult to predict.

The technique proposed here, which relies on $\mathrm{dB} / \mathrm{dt}$ keograms could be an efficient method for other studies of the geomagnetic field disturbances. Murphy et al. [2009] used observations of ULF geomagnetic fluctuations (monitored using a ground magnetometer array) to identify an ionospheric "epicenter" of ULF power and possibly a "birth place" of magnetospheric substorm on a continental scale with a high temporal resolution (better than 1 min) They utilized the wavelet technique to determine the initiation time and power of magnetic fluctuations in the Pi1 band (1-40 s periods). In a similar way, more simple method relying on $\mathrm{dB} / \mathrm{dt}$ keograms could also reveal the latitudinal location of the magnetic variation epicenter and its time evolution during substorm preparation and expansion phases.

In further studies the IMAGE stations will be augmented with Saint-Petersburg (SPG) [Sidorov et al., 2017] and White Sea (WSE) [Gvishiani et al., 2018] observatories at lower latitudes.

\section{Conclusion}

The analysis of geomagnetic data along a latitudinal profile with the use of a magnetic keogram $(\mathrm{dB} / \mathrm{dt})$ plotting technique together with recordings of GIC amplitudes in a power transmission line during 2015 has provided the following preliminary results. Besides substorm onset, nightside MIEs are effective in excitation of GICs. Analysis of the latitudinal geomagnetic profile along longitude $\mathrm{L}^{\sim} 110^{\circ}$ has shown that isolated magnetic pulses may be effective in generation of GIC bursts. At the same time, a quasi-periodic series of magnetic pulses is a typical feature of substorm, known as Ps6 or Pi3 pulsations. Ps6 / Pi3 pulsations have turned out to be very effective in excitation of GICs. The recorded disturbances of GICs associated with Ps6 series are in excess of $20 \mathrm{~A}$. The impact on a power line strongly depends on a location of the $\mathrm{dB} / \mathrm{dt}$ epicenter in respect to its location. The latitudinal scale of $\mathrm{dB} / \mathrm{dt}$ burst, which is $\sim 3^{\circ}-5^{\circ}$, should overlap with the power line position.

Acknowledgements. This work was supported by grant 17-77-20034 from the Russian Science Foundation. We thank the institutes who maintain the IMAGE magnetometer array: Tromsø Geophysical Observatory (Norway), Finnish Meteorological Institute (Finland), Institute of Geophysics (Poland), German Research Centre for Geosciences (Germany), Geological Survey of Sweden (Sweden), Institute of Space Physics (Sweden), Sodankylä Geophysical Observatory (Finland), and Polar Geophysical Institute (Russia). We are very thankful to the Reviewer for an exceptionally thorough consideration of our paper. 


\section{Data and sharing resources.}

The El index is publicly available from IMAGE website (http://space.fmi.fi);

The OP model is written in IDL and was developed at J. Hopkins Applied Physics Laboratory by P. Newell and co-workers (may be freely downloaded from SourceForge). The database with the identified auroral boundaries with the use of the OP model is at (https://www.ngdc.noaa.gov/stp/ovation_prime/data/);

The magnetometer data are publicly available from the IMAGE website (https://space.fmi.fi/image/www);

The GIC data are freely available at the website (http://eurisgic.org).

\section{References}

Amm O., A. Aksnes, J.Stadsnes, , N. Østgaard, R.R. Vondrak, G.A. Germany, G. Lu, A. Viljanen (2005). Mesoscale ionospheric electrodynamics of omega bands determined from ground-based electromagnetic and satellite optical observations, Ann. Geophys. 23, 325-342, doi:10.5194/angeo-23-325-2005.

Apatenkov S.V., V.A. Sergeev, R. Pirjola, A. Viljanen (2004). Evaluation of the geometry of ionospheric current systems related to rapid geomagnetic variations, Ann. Geophys. 22, 63-72.

Belakhovsky V.B., V.A. Pilipenko, Ya.A. Sakharov, V.N. Selivanov (2018). Characteristics of the variability of a geomagnetic field for studying the impact of the magnetic storms and substorms on electrical energy systems, Izvestiya, Phys. Sol. Earth, 54, 52-65, doi:10.1134/S1069351318010032.

Belakhovsky V. V. Pilipenko, M. Engebretson, Ya. Sakharov, V. Selivanov (2019). Impulsive disturbances of the geomagnetic field as a cause of induced currents of electric power lines, J. Space Weather and Spac. 9, A18, doi:10.1051/swsc/2019015.

Bolduc L. (2002). GIC observations and studies in the Hydro-Québec power system, J. Atmos. Terr. Phys. 64, 1793-1802, doi:10.1016/S1364-6826(02)00128-1.

Boteler D.H. (2001). Space weather effects on power systems, in “Space Weather”, eds. Song, P., Singer, H.J. and Siscoe, G., AGU, Washington, 347-352.

Connors M., G. Rostoker, G. Sofko, R.L. McPherron, M.G. Henderson (2003). Ps6 disturbances: Relation to substorms and the auroral oval, Ann. Geophys. 21, 493-508.

Despirak I.V., A.A. Lyubchich, N.G. Kleimenova (2014). Polar and high latitude substorms and solar wind conditions, Geomagn. Aeron. 54, 575-582, doi:10.1134/S0016793214050041.

Engebretson M.J., E.S. Steinmetz, J.L. Posch, V.A. Pilipenko, M.B. Moldwin, M.G. Connors, D.H. Boteler, I.R. Mann, M.D. Hartinger, J.M. Weygand, L.R. Lyons, Y. Nishimura, H.J. Singer, S. Ohtani, C.T. Russell, A. Fazakerley, L.M. Kistler (2019). Multiple-Instrument Observations of Nighttime Magnetic Impulse Events (MIEs) at High latitudes, J. Geophys. Res. Space Phys. 124, doi:10.1029/2019JA026797.

Gvishiani A.D., A.A. Soloviev, Sidorov, R.V., Krasnoperov, R.I., Grudnev, A.A., Kudin, D.V., ... and A.O. Simonyan (2018). Successes of the organization of geomagnetic monitoring in Russia and the near abroad, Vestnik Otdelenia nauk o Zemle RAN 10, 1-24, doi:10.2205/2018nz000357.

Guillon S., P.Toner, L. Gibson, D.A. Boteler (2016). Colorful blackout: the havoc caused by auroral electrojet generated magnetic field variations in 1989, IEEE Power and Energy, 59-71, doi:10.1109/MPE.2016.2591760.

Hapgood M. (2012). Prepare for the coming space weather storm, Nature 484, 311-313.

Henderson M.G., L. Kepko, H.E. Spence, M. Connors, J.B. Sigwarth, L.A. Frank, H.J. Singer, K. Yumoto (2002). The evolution of north-south aligned auroral forms into auroral torch structures: the generation of omega bands and Ps6 pulsations via flow bursts, in: Proceedings of the 6-th International Conference on Substorms, ed.: Winglee, R.M., University of Washington, Seattle, USA.

Kappenman J. (2004). The evolving vulnerability of electric power grids, Adv. Space Res. 2, S01004, doi:/2003SW000028.

Kataoka R., C. Ngwira (2016). Extreme geomagnetically induced currents, Prog. Earth Plan. Sci. 3, 23, doi:10.1186/s40645-016-0101-x.

Keiling A., J.R. Wygant, C. Cattell, M. Temerin, F.S. Mozer, C.A. Kletzing, J. Scudder, C.T. Russell, W. Lotko, A.V. Streltsov (2000). Large Alfven wave power in the plasma sheet boundary layer during the expansion phase of substorms, Geophys. Res. Lett. 27, 3169-3172. 


\section{Olga Kozyreva et al.}

Kleimenova N.G., O.V. Kozyreva, K. Kauristie, J. Manninen, A. Ranta (2002). Case studies on the dynamics of Pi3 geomagnetic and riometer pulsations during auroral activations, Ann. Geophys. 20, 151-159.

Kozyreva, O.V., V.A. Pilipenko, V.B. Belakhovsky, Ya.A. Sakharov (2018). Ground geomagnetic field and GIC response to March 17, 2015, storm, Earth, Planets Space 70,157, doi:10.1186/s40623-018-0933-2.

Love J.J., G.M. Lucas, A. Kelbert, P.A. Bedrosian (2018). Geoelectric hazard maps for the Pacific Northwest, Adv. Space Res. 16, 1114-1127, doi:10.1029/2018SW001844.

Martines-Bedenko V.A., V.A. Pilipenko, M.D. Hartinger, M.J. Engebretson, D.A. Lorentzen, A.N. Willer (2018). Correspondence between the latitudinal ULF wave power distribution and auroral oval in conjugate ionospheres, Sun and Geosphere 13/1, 41-47.

Mende S.B., H.U. Frey, S.P. Geller, J.H. Doolittle (1999). Multistation observations of auroras: Polar cap substorms. J. Geophys. Res. 104, $2333-2342$.

Murphy K.R., I.J. Rae, I.R. Mann, D.K. Milling, C.E.J. Watt, L. Ozeke, H.U. Frey, V. Angelopoulos, C.T. Russell (2009). Wavelet-based ULF wave diagnosis of substorm expansion phase onset, J. Geophys. Res. 114, A00C16, doi:10.1029/2008JA013548.

National Research Council (2008) Severe Space Weather Events: Understanding Societal and Economic Impacts: A Workshop Report. National Academies Press, Washington, doi:10.17226/12507.

Ngwira C.M., D. Sibeck, M.D.V. Silveira, M. Georgiou, J.M. Weygand, Y. Nishimura, D. Hampton (2018). A study of intense local dB/dt variations during two geomagnetic storms, Adv. Space Res. 16, 676-693, doi:10.1029/2018SW001911.

Newell P. T. T. Sotirelis, S. Wing (2009). Diffuse, monoenergetic, and broadband aurora: The global precipitation budget, J. Geophys. Res. 114, A09207, doi:10.1029/2009JA014326.

Newell P.T., K. Liou, Y. Zhang, T. Sotirelis, L.J. Paxton, E.J. Mitchel (2014). OVATION Prime-2013: Extension of auroral precipitation model to higher disturbance levels, Adv. Space Res. 12, 368-379, doi:10.1002/2014SW001056.

Opgenoorth H.J., J. Oksman, K.U. Kaila, E. Nielsen, W. Baumjohann (1983). Characteristics of eastward drifting omega bands in the morning sector aurora. J. Geophys. Res. 88, 9171-9185.

Pulkkinen A. (2015). Geomagnetically induced currents modeling and forecasting, Adv. Space Res. 13, 734- 736, doi:10.1002/2015SW001316.

Sakharov Ya.A. A.N. Danilin, R.M. Ostafiychuk (2007). Registration of GIC in power systems of the Kola Peninsula. Proc. of 7-th symp. on Electromagnetic Compatibility and Electromagnetic Ecology, StPetersburg: 291-293. Institute of Electrical and Electronics Engineers (IEEE), ISBN: 9781424412693

Sergeev V.A., D.A. Yahnin, K. Liou, M.F. Thomsen, G.D. Reeves (2005). Narrow plasma streams as a candidate to populate the inner magnetosphere, in: "The Inner Magnetosphere: Physics and Modeling" (eds. Pulkkinen T.I., N.A. Tsyganenko, R.H. Friedel), doi:10.1029/155GM07.

Sidorov, R., A. Soloviev, R. Krasnoperov, D. Kudin, A. Grudnev, Y. Kopytenko, ... and P. Sergushin (2017). Saint Petersburg magnetic observatory: from Voeikovo subdivision to INTERMAGNET certification. Geosci. Instrument. Meth.6, 473-485. doi:10.5194/gi-6-473-2017.

Tanskanen E.I. (2009). A comprehensive high-throughput analysis of substorms observed by IMAGE magnetometer network: Years 1993-2003 examined. J. Geophys. Res. 114, A05204, doi:10.1029/2008JA013682.

Viljanen, A., (1998). Relation of geomagnetically induced currents and local geomagnetic field variations, IEEE Transactions on Power Delivery, 13, 1285-1290.

Vorobjev V.G., Ya.A. Sakharov, O.I. Yagodkina, A.A. Petrukovich, V.N. Selivanov (2018). Geomagnetically induced currents and their relation with the position of westward electrojet and auroral precipitation boundaries, Proc. of the Kola Scientific Center, doi:10.25702/KSC.2307-5252.2018.9.5.16-28.

Vorobev A.V., V.A. Pilipenko, Ya.A. Sakharov, V.N. Selivanov (2019). Statistical relationships between variations of the geomagnetic field, auroral electrojet, and geomagnetically induced currents, Solar-Terr. Phys. 5, 35-42, doi:10.12737/stp-512019052018.

Yagova N.V., V.A. Pilipenko, E.N. Fedorov, A.D. Lhamdondog, Yu.P. Gusev (2018). Geomagnetically induced currents and space weather: $\mathrm{Pi} 3$ pulsations and extreme values of time derivatives of the geomagnetic field's horizontal components, Izvestiya, Phys. Solid Earth 54, 749-763. doi:10.1134/S1069351318050130. 
Substorm fine structure and GICs

"CORRESPONDING AUTHOR: Vyacheslav PILIPENKO,

Institute of Physics of the Earth, Moscow, Russia and Geophysical Center, Moscow, Russia; e-mail: pilipenko_va@mail.ru

(c) 2020 the Istituto Nazionale di Geofisica e Vulcanologia.

All rights reserved 